\title{
Induction of Drug-Metabolizing Enzymes by Phenobarbital in Layered Co-culture of a Human Liver Cell Line and Endothelial Cells
}

\author{
Maki Ohno, ${ }^{a, b}$ Kiyoto Мотоліма, ${ }^{b}$ Teruo Oкano, ${ }^{c}$ and Akiyoshi Taniguchi $*, a$ \\ ${ }^{a}$ Advanced Medical Materials Group, Biomaterials Center, National Institute for Materials Science, MANA; 1-1 Namiki, \\ Tsukuba, Ibaraki 305-0044, Japan: ${ }^{b}$ Department of Biochemistry, Meiji Pharmaceutical University; 2-522-1 Noshio, \\ Kiyose, Tokyo 204-8588, Japan: and ${ }^{c}$ Institute of Advanced Biomedical Engineering and Science, Tokyo Women's Medical \\ University; 8-1 Kawada-cho, Shinjuku-ku, Tokyo 162-8666, Japan. \\ Received November 26, 2008; accepted February 24, 2009; published online February 27, 2009
}

Primary human hepatocytes are extensively used to study the potential of drugs to induce cytochrome $\mathbf{P 4 5 0}$ (CYP). However, the activities of these enzymes decrease rapidly during culture. Previously we reported that in a layered co-culture system with HepG2 and bovine endothelial cells, the expression levels of various CYP genes were significantly increased compared with the monolayer cultured HepG2 cells. Here, we examined the induction of CYP gene expression by an inducer by examining the effect of phenobarbital treatment on CYP gene expression in the co-culture system. In the layered co-cultured HepG2, expression of the CYP2C and CYP3A family genes was induced by phenobarbital treatment. We also detected CYP3A4 enzyme induction using this co-culture system. Moreover, the induction of hepatic drug transporters by phenobarbital was detected. These results suggest that functional regulation of the CYP and transporter gene pathway is retained in these layered co-cultured cells. Thus, this system may serve as a useful model for in vitro pharmacological studies on the coordinated regulation of transport and metabolism.

Key words hepatocyte; cytochrome P450; co-culture; gene expression

Primary culture of human hepatocytes is a useful in vitro system to study the potential of drugs to induce cytochrome P450 (CYP $)^{1,2)}$ and to analyze the activity and regulation of drug uptake and efflux transporters. ${ }^{3-5)}$ Indeed, human hepatocytes exhibit the entire repertoire of hepatic drug-metabolizing enzymes, drug transporters and the genes for liver-specific functions. ${ }^{6,7)}$ However, the expression of many proteins has been shown to decrease rapidly in cultured primary hepatocytes, with drug metabolizing enzymes being particularly sensitive. ${ }^{8}$ Liver slices retain metabolic function longer than primary hepatocytes ${ }^{9}{ }^{9}$ however drug metabolism decreases rapidly upon incubation, and the erratic supply of human liver tissue is a major problem.

The human hepatocyte cell line HepG2 is also a useful in vitro model for investigation of the metabolism and toxicity of drugs, as these cells retain many of the specialized functions which are characteristic of normal human hepatocytes and are easy to manipulate. ${ }^{10,11)}$ However, the gene expression levels and activity of drug-metabolizing enzymes in this cell line are lower than in primary hepatocytes, ${ }^{12-14)}$ and induction of the CYP genes by inducers is not observed in HepG2 and other cell lines. ${ }^{15,16)}$ Thus, a more functional culture system is required to obtain the usually high levels of activity and regulation ability of drug metabolizing systems.

Previously we reported the development of a culture surface produced using a thermo-responsive polymer, $\operatorname{poly}(\mathrm{N}$ isopropylacrylamide) (PIPAAm). ${ }^{17,18)}$ Using this thermo-responsive surface, we assembled a layered co-culture system consisting of hepatic cells and sheets of endothelial cells, which allows for continuous expression of the differentiated functions of hepatocytes. In addition, expression of albumin and apolipoprotein A-1 increase ${ }^{19)}$ and numerous hepatocyte and endothelial cell functions increase in intensity upon a layered co-culture system. ${ }^{20)}$ We also reported that in a layered co-culture system with HepG2 cells and bovine pulmonary artery endothelial cells (BPAECs) forming a sheet, the gene expression levels of various CYP and other drugmetabolizing enzymes were significantly increased, compared with the monolayer cultured HepG2 cells, and were maintained at high levels for extended periods. ${ }^{21)}$

The present study analyzed the drug metabolism of this layered co-culture system. To study the induction of CYP expression by an inducer in the co-culture system, we analyzed the effect of phenobarbital treatment on CYP expression in the layered co-cultured HepG2 cells. The gene expression of CYP2C and CYP3A and activity of CYP3A4 were induced by phenobarbital in a concentration-dependent manner. Furthermore, the induction of hepatic drug transporters was detected in the layered co-cultured HepG2 cells. These results indicate that the functions of CYP and drug transporters are retained in the layered co-cultured cells, making it a useful model for drug metabolism analysis.

\section{MATERIALS AND METHODS}

Cells and Cell Culture M2 HepG2 cells ${ }^{22)}$ were cultured in Dulbecco's modified Eagle's medium (SigmaAldrich, St. Louis, MO, U.S.A.) supplemented with $10 \%$ fetal bovine serum, $100 \mathrm{U} / \mathrm{ml}$ penicillin and $100 \mu \mathrm{g} / \mathrm{ml}$ streptomycin at $37{ }^{\circ} \mathrm{C}$ in a humidified atmosphere with $5 \% \mathrm{CO}_{2}$. HepG2 cells were plated on type I collagen-coated plastic dishes (35 $\mathrm{mm}$ in diameter) (Iwaki, Tokyo, Japan) at a cell density of $1.0 \times 10^{6}$ cells/dish.

BPAECs were purchased from Cell Applications, Inc. (San Diego, CA, U.S.A.) and cultured in EBM medium supplemented with $5 \%$ fetal bovine serum, $12 \mu \mathrm{g} / \mathrm{ml}$ bovine brain extract, $1 \mu \mathrm{g} / \mathrm{ml}$ hydrocortisone, $10 \mathrm{ng} / \mathrm{ml}$ human epidermal growth factor, $50 \mu \mathrm{g} / \mathrm{ml}$ gentamycin, and $50 \mathrm{ng} / \mathrm{ml}$ amphotericin B using the EGM-MV BulletKit (Cambrex Bio Science Walkersville, Inc., Wakersville, MD, U.S.A.) at $37^{\circ} \mathrm{C}$ in a humidified atmosphere with $5 \% \mathrm{CO}_{2}$ and $95 \%$ air. BPAECs with 4-5 population-doubling levels were plated on PI- 
a

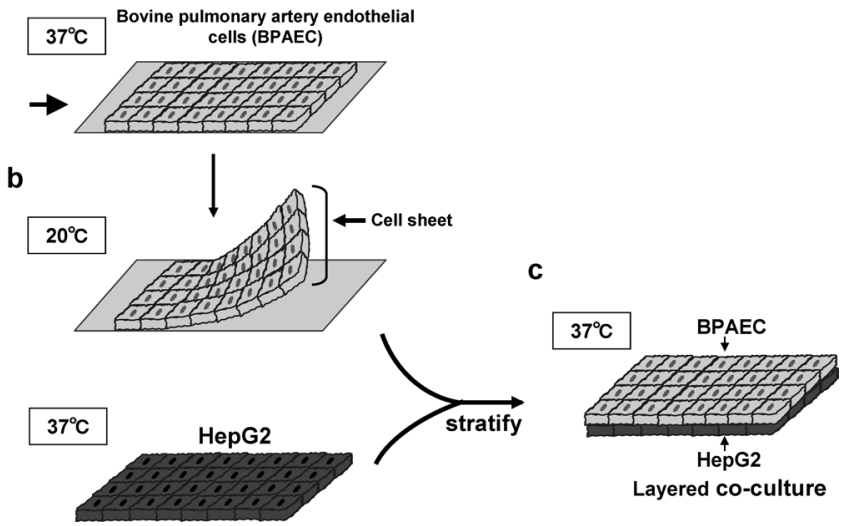

Fig. 1. Schematic Representation of the Construction of the Layered Coculture System Using Temperature-Sensitive Polymer Grafted Surfaces

(a) BPAEC cells are seeded on the PIPAAm-coated dishes and BPAEC sheets grown at $37^{\circ} \mathrm{C}$. (b) The temperature is decreased to $20^{\circ} \mathrm{C}$ to induce the detachment of BPAEC sheets. (c) BPAEC sheets are stratified to HepG2 and assembled into a layered co-culture system.

PAAm-coated UpCell dishes (35 mm in diameter) (CellSheed, Tokyo, Japan) and type I collagen-coated plastic dishes.

Layered Co-culture of HepG2 Cells and BPAEC Sheets Construction of the layered co-cultured cells was as follows (see Fig. 1). HepG2 cells were cultured at $37^{\circ} \mathrm{C}$ until confluence and co-cultured with stratified BPAEC sheets. The 3-dimensional manipulation of the BPAEC sheets and assembly of the layered co-cultured cells were performed as previously described. ${ }^{19-21)}$ Briefly, BPAECs were plated on the UpCell dishes at a cell density of $1.0 \times 10^{6}$ cells/dish and cultured for 1 week at $37^{\circ} \mathrm{C}$. After removing the culture medium, a sheet of polyvinylidene fluoride (PVDF) membrane (Millipore, Billerica, MA, U.S.A.) was placed over the BPAEC monolayer. The dishes were then moved to a $\mathrm{CO}_{2}$ incubator at $20^{\circ} \mathrm{C}$ for $5 \mathrm{~min}$, during which the BPAEC sheets detach spontaneously from the dish surfaces. The overlaid PVDF membrane, together with the BPAEC sheet, was peeled off the dishes and transferred onto a monolayer of HepG2 cells. After incubation at $37^{\circ} \mathrm{C}$ for $2 \mathrm{~h}$, the PVDF membrane was removed from the BPAEC sheet using tweezers. The stratified sheets were then cultured in a mixture of EBM medium and Dulbecco's modified Eagle's medium ( $1: 1, \mathrm{v} / \mathrm{v}$ ratio) at $2 \mathrm{ml}$ of medium/dish.

Treatment of Cells with Phenobarbital Phenobarbital stock solutions were prepared in dimethyl sulfoxide (DMSO) and diluted directly into assay medium. The final DMSO concentration of $0.5 \%$ was maintained in all dilutions. The monolayer culture and layered co-cultured cells at $21 \mathrm{~d}$ after overlaying the BPAEC sheet onto HepG2 cells were treated with phenobarbital by replacing the medium in each dish with $2 \mathrm{ml}$ of medium containing 0.5 or $1.0 \mathrm{~mm}$ of phenobarbital or DMSO control and incubated for $48 \mathrm{~h}$.

RNA Isolation and cDNA Synthesis Total RNAs from mixture of HepG2 and BPAEC cells or HepG2 cells were extracted using RNAiso (Takara, Kyoto, Japan) according to the manufacturer's protocol and quantified by measuring absorbance at $260 \mathrm{~nm}$; purity was assessed from the 260: $280 \mathrm{~nm}$ absorbance ratio. cDNA for real time polymerase chain reaction (PCR) was synthesized by reverse transcrip-
Table 1. Sequences of Oligonucleotide Primers for Real-Time PCR

\begin{tabular}{|c|c|}
\hline Gene name & Sequence \\
\hline \multirow[t]{2}{*}{ CYP2C9 } & Forward: 5'-CTTTGCACTATCTGTAATGCCTTTTC-3' \\
\hline & Reverse: 5'-TGGAGGTCGAATGTTCACTAGATC-3' \\
\hline \multirow[t]{2}{*}{ CYP3A4 } & Forward: 5'-TGCTTCTCACGGGACTATTTCC-3' \\
\hline & Reverse: 5'-TCTTATCAGAGCTCAGGAGGAGTTAA-3' \\
\hline \multirow{2}{*}{ CYP3A7 } & Forward: 5'-CTCCTGAGCTCTGATAACATAATTAACATT-3' \\
\hline & Reverse: 5'-CTGTTAGAGCCATCAAAATAATTCCTATTT-3' \\
\hline \multirow[t]{2}{*}{ CYP4A11 } & Forward: 5'-CCCCTTGTGGCCTTTGG-3' \\
\hline & Reverse: 5'-GCGTCAGGGTAGCCTTCCA-3' \\
\hline \multirow{2}{*}{ BSEP } & Forward: 5'-ATATGAGGGAAAACCCAATGTCA \\
\hline & Reverse: 5'-ACTGGCTCCTGCACAGAGAAG \\
\hline \multirow[t]{2}{*}{ MRP2 } & Forward: 5'-CCATGGGTTAGAAAAGGACTATAAGAAT \\
\hline & Reverse: 5'-TTATTTTCTTAACCTGGGTAGTAGGTTCA \\
\hline \multirow[t]{2}{*}{ GAPDH } & Forward: 5'-GGAGTCCCTGCCACACTCAG-3' \\
\hline & Reverse: 5'-GGCCCCTCСССТCTTCA-3' \\
\hline
\end{tabular}

BSEP: bile salt export pump MRP2: multidrug resistance-associated protein

tion of $4 \mu \mathrm{g}$ of total RNA with random hexamer primers and Super Script II reverse transcriptase (Invitrogen, Carlsbad, CA, U.S.A.) according to the manufacturer's protocol.

Real-time PCR Using the SYBR Green I Method Real-time PCR was performed using an ABI PRISM 7000 Sequence Detection System (Applied Biosystems, Forster City, CA, U.S.A.). The standard reaction was performed in a 96-well plate and was composed of $10 \mu \mathrm{l}$ of SYBR Premix Ex Taq $^{\mathrm{TM}}$ II (Takara), $10 \mathrm{pmol}$ each of the forward and reverse primers, $40 \mathrm{ng}$ of HepG2 or BPAEC cDNA, and distilled water, to a final volume of $20 \mu \mathrm{l}$. To create a standard curve, a series of diluted standard plasmids, ranging from $1.8 \times 10^{7}$ to $1.8 \times 10^{3}$ copies $/ \mu 1$, was used instead of HepG 2 or BPAEC cDNA and were amplified at the same time. The thermocycling conditions were $95^{\circ} \mathrm{C}$ for $10 \mathrm{~s}$, following by 40 cycles of $95^{\circ} \mathrm{C}$ for $5 \mathrm{~s}$ and $60^{\circ} \mathrm{C}$ for $31 \mathrm{~s}$.

Species-specific primers against a region of low-homology between human and bovine cDNA were designed using Primer Express Software (ver. 2.0, Applied Biosystems) (Table 1). Data were normalized to corresponding glyceraldehyde 3-phosphate dehydrogenase (GAPDH) gene expression levels, and the mRNA expression levels are indicated as fold-induction.

Measurement of CYP3A4 Enzyme Activity CYP3A4 activity was measured in layered co-cultured cells and monolayer cells using the P450-Glo ${ }^{\mathrm{TM}}$ CYP3A4 Assay with Luciferin-PFBE (Promega, Madison, WI, U.S.A.). Luminogenic substrate for CYP3A4 was added to the layered co-cultured cells and monolayer cells and these cells were then incubated for $3 \mathrm{~h}$. Luciferin detection reagent was added to each cell culture medium, and luminescence was read by a luminometer. The luminescence data were normalized against cell number for each cell culture dish.

Statistical Analysis Data are presented as mean \pm standard deviation (S.D.). Single group comparisons were evaluated using the Wilcoxon rank sum test. $p<0.05$ was regarded as significant.

\section{RESULTS}

HepG2 cells are useful for investigation of the metabolism and toxicity of drugs. ${ }^{10,11)}$ However, induction of the CYP genes by inducers is not observed in HepG2 cells. ${ }^{15,16)} \mathrm{We}$ 

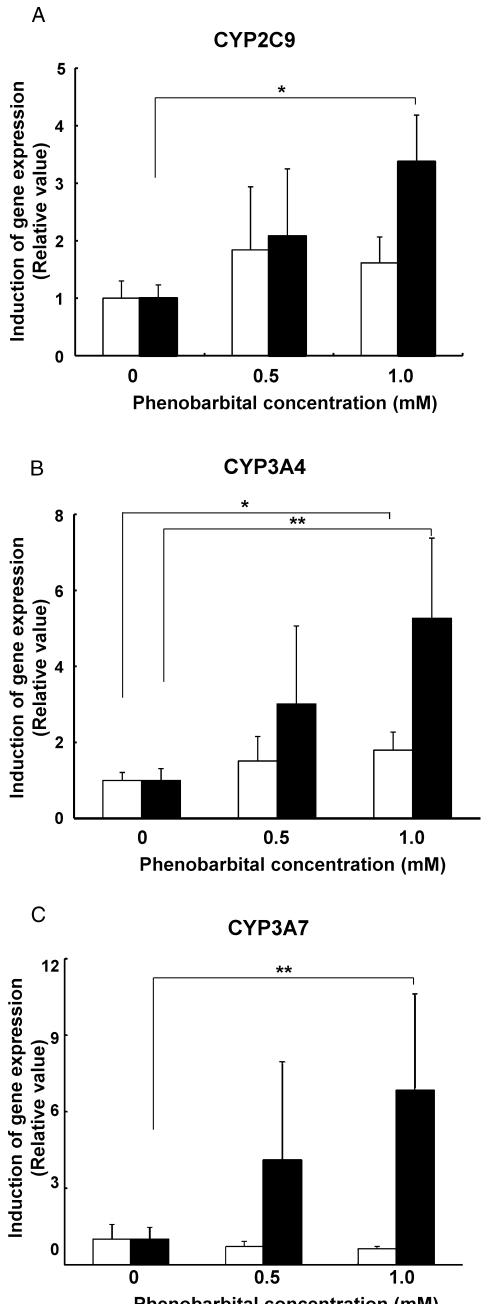

D

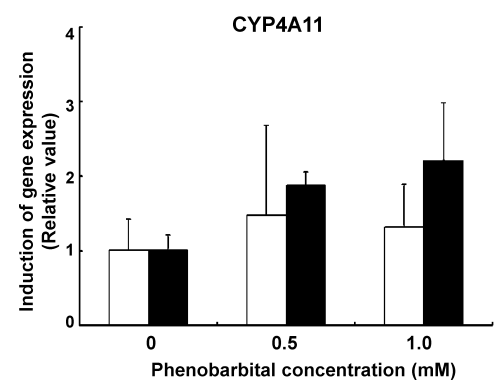

Fig. 2. The Effect of Phenobarbital Treatment on CYP Gene Expression in the Layered Co-cultured Cells

The relative gene expression levels of CYP2C9 (A), CYP3A4 (B), CYP3A7 (C) and CYP4A11 (D) are shown as folds of induction. The layered co-cultured cells (solid bars) consisted of a BPAEC sheet overlaid onto hepatic HepG2 cells. Open bars show the CYP gene expressions in the mono-layered HepG2 cells. After $21 \mathrm{~d}$, these cells were treated with phenobarbital $(0.5$ or $1.0 \mathrm{~mm})$ for $48 \mathrm{~h}$, and then total RNA was isolated from the cells. After synthesizing cDNA from total RNA, the gene expression levels were analyzed by real-time PCR. Each value represents the mean \pm standard deviation from five separate experiments. Error bars indicate the standard deviation of mean changes. $* p<0.05 ; * * p<0.01$.

previously reported that in the layered co-cultured cells, consisting of a BPAEC sheet overlaid onto HepG2 cells, the gene expression levels of CYP2C9, CYP3A4 and CYP3A7 were significantly increased compared with monolayer cultured HepG2 cells. ${ }^{21)}$ The results suggested that our co-culture system would be suitable for drug metabolism analysis. To perform further functional analysis of the co-culture sys-

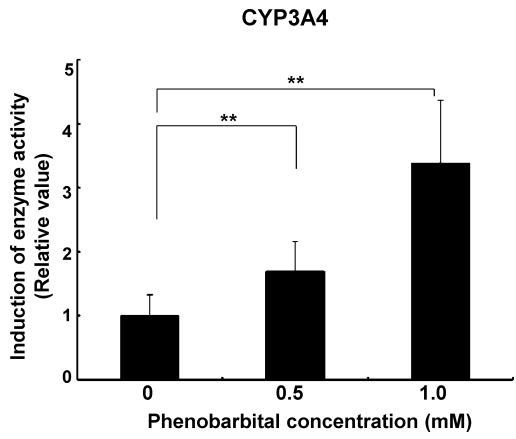

Fig. 3. The Effect of Phenobarbital Treatment on CYP3A4 Activity in the Layered Co-cultured Cells

Relative changes in enzyme activity are shown as fold induction. HepG2 cells were overlaid with BPAEC sheet cells. After $21 \mathrm{~d}$, co-cultured cells were treated with phenobarbital $(0.5$ or $1.0 \mathrm{~mm})$ for $48 \mathrm{~h}$. Each value represents the mean \pm standard deviation from five separate experiments. Error bars indicate the standard deviation of mean changes. $* * p<0.01$.

tem, we examined the effect of phenobarbital ( 0.5 or $1 \mathrm{~mm})$ treatment on CYP gene expression in the layered co-cultured HepG2 cells by real-time PCR analysis using primers specific for human genes (Figs. 2A-D). Phenobarbital is known to induce the gene expression of CYP2C and CYP3A in human primary hepatocytes and liver slices. ${ }^{23,24)}$ The primers used were designed from regions of low-homology between human and bovine cDNA to avoid cross-amplification of CYP2C9, CYP3A4, CYP3A7 and CYP4A11 (Table 1). The gene expression levels of CYP2C9, CYP3A4 and CYP3A7 in the layered co-cultured HepG2 cells after treatment with $1 \mathrm{~mm}$ phenobarbital were significantly higher than that observed in untreated cells (Figs. 2A-C). Treatment of the layered co-cultured cells with $1 \mathrm{~mm}$ phenobarbital induced 3.4-, 5.3- and 6.8-fold increases in the gene expression levels of CYP2C9, CYP3A4 and CYP3A7, respectively. However, treatment of the monolayer cultured HepG2 cells with 0.5 or $1 \mathrm{~mm}$ phenobarbital did not cause significant increases in the gene expressions levels of CYP2C9 and CYP3A7, while the relative induction of CYP3A4 expression was lower than that observed in the layered co-cultured cells. CYP4A11 is not induced by phenobarbital in human liver slices. ${ }^{25)}$ There were no significant differences in relative induction of CYP4A11 gene expression between the layered co-culture and monolayer culture of HepG2 after treatment with 0.5 or $1 \mathrm{~mm}$ phenobarbital (Fig. 2D). These findings indicate that the layered co-cultured HepG2 cells exhibit a profile of regulation of CYP genes close to that found in human primary hepatocytes and liver slices.

The measurement of enzyme activity is suitable for highthroughput analysis compared with measuring the gene expression levels during preclinical development. However, it is very difficult to measure the CYP activity in HepG2 cells, because CYP activity occurs at significantly low levels in HepG2 cells. ${ }^{13)}$ We previously reported that in the layered co-cultured HepG2 cells, the gene expression level of the CYP3A4 was about 100 times greater than monolayer cultured HepG2 cells. ${ }^{21)}$ In the present study, we measured the CYP3A4 activity in the layered co-cultured HepG2 cells. Figure 3 shows the relative CYP3A4 activity in the layered co-culture at $21 \mathrm{~d}$ after overlaying the BPAEC sheet onto hepatic HepG2 cells. Treatment with phenobarbital at 0.5 and $1 \mathrm{~mm}$ resulted in a 1.7- and 3.4-fold increase, respectively, in 


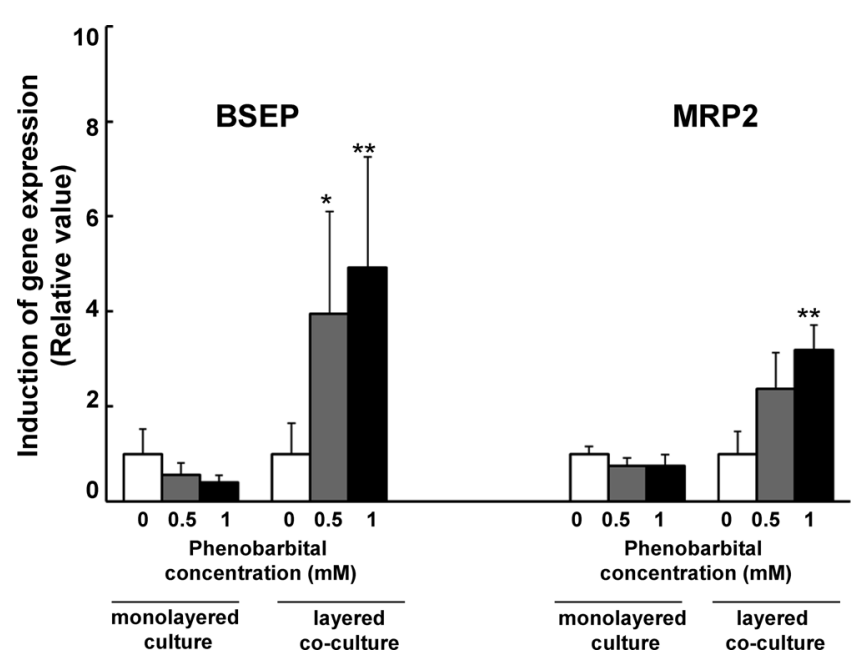

Fig. 4. The Effect of Phenobarbital on BSEP and MRP2 Gene Expression in the Layered Co-cultured Cells

Relative changes in BSEP and MRP2 gene expression are shown as fold induction. The layered co-cultured HepG2 cells and monolayer cultured HepG2 cells were cultured for $21 \mathrm{~d}$. These cells were treated with phenobarbital $0.5 \mathrm{~mm}$ (gray bars) and $1.0 \mathrm{~mm}$ (black bars) for $48 \mathrm{~h}$ and then total RNA isolated from the cells. After synthesizing cDNA from total RNA, the gene expression levels were analyzed by real-time PCR. Data were normalized to corresponding GAPDH gene expression levels. Each value represents the mean \pm standard deviation from five separate experiments. Error bars indicate the standard deviation of mean changes. $* p<0.05 ; * * p<0.01$.

the CYP3A4 activity in the layered co-cultured cells. In our previous study, the CYP3A4 activity in the layered co-cultured cells increased 3.4-fold compared to that in the monolayer culture cells. ${ }^{21)}$ These results indicate that the increased expression of the cytochrome P450 mRNAs correlates with increased CYP enzyme activity.

In human primary hepatocytes and liver slices, transporter expression has been shown to be regulated by phenobarbital treatment. $^{21,26)}$ We examined the effects of phenobarbital treatment on hepatic transporter mRNA expression (Fig. 4). The gene expression of the canalicular bile salt export pump (BSEP) in the layered co-cultured HepG2 cells after treatment with phenobarbital at 0.5 and $1 \mathrm{~mm}$ resulted in a 3.9and 4.9-fold increase, respectively, compared with untreated cells. Treatment of the layered co-cultured cells with $1 \mathrm{~mm}$ phenobarbital induced a 3.2-fold increase in the gene expression level of the efflux transporter multidrug resistance-associated protein 2 (MRP2). However, in the monolayer cultured HepG2 cells treatment with 0.5 or $1 \mathrm{~mm}$ phenobarbital did not cause significant increases in the gene expression levels of BSEP or MRP2. The expression levels of MRP2 and BSEP genes were not significantly different between layered co-cultured and monolayer cultured HepG2 cells (data not shown). These results indicate that the layered co-cultured HepG2 cells exhibit a profile of regulation of drug transporters close to that found in human primary hepatocytes and liver slices.

\section{DISCUSSION}

Phenobarbital-mediated induction of drug metabolism enzymes mainly occurs via the nuclear receptors, constitutive androstane receptor (CAR) and pregnane $\mathrm{X}$ receptor (PXR). ${ }^{27-29)}$ CAR plays a role in the expression of CYP2C9 and could potentially play a role in phenobarbital inducibility in humans. ${ }^{15)}$ Phenobarbital has also been shown to induce the CYP3A4 gene expression through a CAR- and PXRmediated signaling pathway. CAR directly transactivates the CYP3A4 xenobiotic responsive element (ER6/DR3), which serves as a $\mathrm{PXR} /$ retinoid $\mathrm{X}$ receptor binding site. ${ }^{27,28,30)} \mathrm{At}$ high concentrations, phenobarbital directly activates human PXR. ${ }^{30,31)}$ The gene expression levels of CAR were not significantly different between phenobarbital treated layered cocultured and monolayer cultured HepG2 cells and the expression levels of PXR fell below the detection limit of the assay (data not shown). These results suggest that induction of CYP2C and CYP3A family genes by phenobarbital in layered co-cultured cells were not regulated by up-regulated basal expression of CAR and PXR mRNA. Takagi et al. reported that PXR protein level was not associated with PXR mRNA level in human livers. ${ }^{32)}$ Further research is needed to examine the relationship between induction of CYP genes and transcription factors in layered co-culture cells.

We detected CYP3A4 enzyme induction using the layered co-cultured HepG2 cells. Treatment with $1 \mathrm{~mm}$ phenobarbital resulted in a 3.4-fold increase in CYP3A4 activity (Fig. 3). In human primary hepatocytes, the average magnitude of induction by phenobarbital $(250 \mu \mathrm{M})$ on CYP3A4 activity was approximately 3.3-fold. ${ }^{33)}$ However, induction of CYP3A4 activity by phenobarbital was not detected in HepG2 cells. ${ }^{13)}$ These results indicate that in the layered co-culture system induction levels of CYP3A4 by phenobarbital were similar levels to that of in human primary hepatocytes. The measurement of enzyme activity is suitable for high-throughput analysis compared with measuring the gene expression.

Of the drug metabolizing enzymes, the hepatic transporters are now recognized as major players contributing to pharmacokinetics, drug-drug interactions and drug adverse effects, underlining the need for convenient cellular models to analyze drug-transporter interactions during preclinical evaluation of drug candidates. ${ }^{34)}$ In the present study, the gene expression of MRP2 was induced by phenobarbital treatment of the layered co-cultured cells (Fig. 4); this induction has also been detected in human primary hepatocytes and human liver slices upon phenobarbital treatment. ${ }^{26,35)}$ The expression of BSEP was upregulated by phenobarbital in the layered co-cultured cells (Fig. 4), and this result also corresponded to that in human liver slices. ${ }^{35)}$ These results suggest that in our layered co-cultured cells drug transporters are regulated in a functionally similar manner to that in human liver slices.

In the present study, we focused on phase I enzymes such as the CYP proteins and drug transporters. However, phase II enzymes are also important for drug metabolism. We previously showed in our layered co-culture system that the expression levels of some phase II enzyme genes, such as glutathione $S$-transferases and $\mathrm{N}$-acetyltransferase, also increase. $^{21)}$

In summary, our data demonstrate that the layered coculture system, consisting of a BPAEC sheet overlaid onto HepG2 cells, displays the expression of CYP genes, phase II enzyme genes and drug transporters. In addition, we detected CYP3A4 enzyme induction using this system. The layered co-culture system also retained functional regulation of the CYP and transporter gene pathway, and can serve as a useful model for in vitro pharmacological studies of the coordinated regulation of transport and metabolism. 


\section{REFERENCES}

1) LeCluyse E. L., Eur. J. Pharm. Sci., 13, 343-368 (2001).

2) Worboys P. D., Carlile D. J., Xenobiotica, 31, 539—556 (2001).

3) Jigorel E., Le Vee M., Boursier-Neyret C., Bertrand M., Fardel O., Drug Metab. Dispos., 33, 1418-1422 (2005).

4) Payen L., Courtois A., Campion J. P., Guillouzo A., Fardel O., Biochem. Pharmacol., 60, 1967-1975 (2000).

5) Payen L., Sparfel L., Courtois A., Vernhet L., Guillouzo A., Fardel O., Cell Biol. Toxicol., 18, 221-233 (2002).

6) Baranczewski P., Stanczak A., Sundberg K., Svensson R., Wallin A., Jansson J., Garberg P., Postlind H., Pharmacol. Rep., 58, 453-472 (2006).

7) Raucy J. L., Drug Metab. Dispos., 31, 533-539 (2003).

8) Binda D., Lasserre-Bigot D., Bonet A., Thomassin M., Come M. P., Guinchard C., Bars R., Jacqueson A., Richert L., Toxicol. In Vitro, 17, 59-67 (2003).

9) de Graaf I. A., Draaisma A. L., Schoeman O., Fahy G. M., Groothuis G. M., Koster H. J., Cryobiology, 54, 1-12 (2007).

10) Knowles B. B., Howe C. C., Aden D. P., Science, 209, 497-499 (1980).

11) Shimada T., Inoue K., Suzuki Y., Kawai T., Azuma E., Nakajima T., Shindo M., Kurose K., Sugie A., Yamagishi Y., Fujii-Kuriyama Y., Hashimoto M., Carcinogenesis, 23, 1199-1207 (2002).

12) Rodriguez-Antona C., Donato M. T., Boobis A., Edwards R. J., Watts P. S., Castell J. V.Gomez-Lechon M. J., Xenobiotica, 32, 505-520 (2002).

13) Westerink W. M., Schoonen W. G., Toxicol. In Vitro, 21, 1581-1591 (2007).

14) Wilkening S., Stahl F., Bader A., Drug Metab. Dispos, 31, 10351042 (2003).

15) Ferguson S. S., LeCluyse E. L., Negishi M., Goldstein J. A., Mol. Pharmacol., 62, 737-746 (2002).

16) Phillips A., Hood S. R., Gibson G. G., Plant N. J., Drug Metab. Dispos., 33, 233-242 (2005).

17) Okano T., Yamada N., Okuhara M., Sakai H., Sakurai Y., Biomaterials, 16, 297-303 (1995).

18) Okano T., Yamada N., Sakai H., Sakurai Y., J. Biomed. Mater. Res., 27, 1243-1251 (1993).

19) Kurosawa Y., Taniguchi A., Okano T., Tissue Eng., 11, 1650-1657
(2005).

20) Takayama G., Taniguchi A., Okano T., Tissue Eng., 13, 159-166 (2007).

21) Ohno M., Motojima K., Okano T., Taniguchi A., Tissue Eng. Part A, 11, 1861-1869 (2008)

22) Hewitt N. J., Hewitt P., Xenobiotica, 34, 243-256 (2004).

23) Matsunaga T., Maruyama M., Harada E., Katsuyama Y., Sugihara N., Ise H., Negishi N., Ikeda U., Ohmori S., Biochem. Biophys. Res. Commun., 318, 428-434 (2004).

24) Raucy J. L., Mueller L., Duan K., Allen S. W., Strom S., Lasker J. M., J. Pharmacol. Exp. Ther, 302, 475-482, (2002).

25) Edwards R. J., Price R. J., Watts P. S., Renwick A. B., Tredger J. M., Boobis A. R., Lake B. G., Drug Metab. Dispos., 31, 282-288 (2003).

26) Jigorel E., Le Vee M., Boursier-Neyret C., Parmentier Y., Fardel O., Drug Metab. Dispos., 34, 1756-1763 (2006).

27) Sueyoshi T., Kawamoto T., Zelko I., Honkakoski P., Negishi M., J. Biol. Chem., 274, 6043-6046 (1999).

28) Xie W., Barwick J. L., Simon C. M., Pierce A. M., Safe S., Blumberg B., Guzelian P. S., Evans R. M., Genes Dev., 14, 3014-3023 (2000).

29) Xu C., Li C. Y., Kong A. N., Arch. Pharm. Res., 28, 249-268 (2005).

30) Moore L. B., Parks D. J., Jones S. A., Bledsoe R. K., Consler T. G., Stimmel J. B., Goodwin B., Liddle C., Blanchard S. G., Willson T. M., Collins J. L., Kliewer S. A., J. Biol. Chem., 275, 15122-15127 (2000).

31) Jones S. A., Moore L. B., Shenk J. L., Wisely G. B., Hamilton G. A., McKee D. D., Tomkinson N. C., LeCluyse E. L., Lambert M. H., Willson T. M., Kliewer S. A., Moore J. T., Mol. Endocrinol., 14, 27-39 (2000).

32) Takagi S., Nakajima M., Mohri T., Yokoi T., J. Biol. Chem., 283, 9674-9680, (2008).

33) Madan A., Graham R. A., Carroll K. M., Mudra D. R., Burton L. A., Krueger L. A., Downey A. D., Czerwinski M., Forster J., Ribadeneira M. D., Gan L. S., LeCluyse E. L., Zech K., Robertson P. Jr., Koch P., Antonian L., Wagner G., Yu L., Parkinson A., Drug Metab. Dispos., 31, 421-431 (2003)

34) Mizuno N., Sugiyama Y., Drug Metab. Pharmacokinet., 17, 93-108 (2002).

35) Olinga P., Elferink M. G., Draaisma A. L., Merema M. T., Castell J. V., Perez G., Groothuis G. M., Eur. J. Pharm. Sci., 33, 380-389 (2008). 